\title{
A qualificação profissional dos trabalhadores na perspectiva do Serviço Social: notas críticas
}

\author{
The professional qualification of workers from the perspective \\ of Social Work: critical notes
}

Angela Santana do Amaral*

\begin{abstract}
Resumo: O texto discute as iniciativas de qualificação profissional implementadas nas últimas décadas, no Brasil, como parte da agenda política dos governantes para enfrentar o problema do desemprego. Mostra como as reais necessidades de educação dos trabalhadores são absorvidas pelo capital, através da apropriação do tempo de vida do trabalhador, do seu conhecimento e das qualificações adquiridas no seu trabalho. Apresenta o movimento através do qual a política de qualificação profissional se transforma em objeto da ação política do Estado, dos empresários e dos sindicalistas e, sob o discurso da sociedade do conhecimento, das habilidades e competências individuais constrói uma nova cultura do trabalho. Por fim, evidencia os desafios do Serviço Social diante das demandas do mercado de trabalho para elaborar e operacionalizar programas de qualificação no âmbito das políticas sociais.
\end{abstract}

Palavras-chave: qualificação profissional; trabalho; conhecimento; Serviço Social.

\begin{abstract}
The text discusses the initiatives of professional qualification implemented in recent decades in Brazil, as part of the political agenda of rulers to face the unemployment problem. Shows how the real education needs of the workers are absorbed by capital through the appropriation of the lifetime of the worker, the knowledge and skills acquired in their work. Shows the movement through which the professional qualification policy becomes the object of political action of the state and of business and union leaders, and in the discourse of the knowledge, skills and individual competencies builds a new work culture. Finally, highlights the challenges of social work given the demands of the labor market to develop and operate qualification programs in social policies.
\end{abstract}

Keywords: professional qualification; work; knowledge; social work.

\footnotetext{
* Assistente Social, Doutora em Serviço Social pela Universidade Federal do Rio de Janeiro (UFRJ). Docente do Departamento de Serviço Social da Universidade Federal de Pernambuco (UFPE) e pesquisadora do Grupo de Estudos e Pesquisas sobre o Trabalho. Correspondência: Rua Rodrigues Ferreira, 45/1104, Bloco F - Várzea - CEP: 50810-020. Recife - Pernambuco/ PE. E-mail: <angelaufpe@yahoo.com.br>.
} 


\section{Introdução}

O final da década de 80 e o prolongamento dos anos 90 do passado século vinte são marcados por profundas mudanças no capitalismo contemporâneo. Do ponto de vista tanto da conjuntura internacional quanto da conjuntura nacional, tais mudanças exprimem o vigor de uma permanente reestruturação para enfrentamento da crise de acumulação capitalista.

Impulsionada por processos econômicos e políticos que incidem na totalidade da vida social, esta crise supõe o desenvolvimento de estratégias que visam recriar as bases de valorização e dominação ideológica do capital. Para tanto, o capital transforma a sua base material de modo a permitir um novo ordenamento das forças produtivas e, ao mesmo tempo, atualiza as práticas de organização político-social das classes em presença.

Trata-se de um movimento que repõe, sob novas bases, alguns elementos da racionalidade anterior, dotando-a de renovados mecanismos capazes de impor as condições para realizar-se enquanto única perspectiva histórica dessa totalidade social.

É esse aspecto político como mediação da reestruturação econômica que queremos enfatizar neste texto. Dentre as inúmeras iniciativas que são implementadas para responder à crise capitalista, a qualificação profissional se apresenta, nos países desenvolvidos e, particularmente, no Brasil, com uma dupla perspectiva: como uma temática central que parece renovar o debate sobre a crise de acumulação e seu enfrentamento e, nesse sentido, tende a envolver todas as classes sociais; e como possibilidade de que esta estratégia viabilize o aumento da produtividade do capital, sua competitividade e se constitua em alternativa ao quadro de desemprego crescente instalado no capitalismo contemporâneo.

Assim, é fundamental para o capital que a ideia da qualificação profissional possa ser tomada, de modo indiferenciado e consensual, por todas as classes sociais, como uma importante estratégia que permite apontar saídas para a crise capitalista. Apresentando o discurso sobre a massificação dos processos de qualificação profissional e sua funcionalidade para a retomada do crescimento econômico, capital e trabalho, com a mediação do Estado, transformam esse argumento em um discurso ideológico capaz de mostrar que é possível a toda a sociedade ter interesses que são comuns ou universais.

Na realidade, o que se pretende com esse argumento ideológico é construir as bases de uma hegemonia dominante, pela via da dissolução dos antagonismos classistas e da mobilização de interesses em torno de um projeto que, embora historicamente reivindicado pelo trabalho, é transformado em necessidade do capital para responder às suas exigências e in- 
corporado pelos trabalhadores como possibilidade de acesso aos processos educacionais, ao longo dos anos, negado pelas classes dominantes ${ }^{1}$.

As iniciativas de qualificação profissional passam a integrar a agenda de organismos internacionais; converte-se em objeto de ação política do Estado, dos empresários e dos sindicalistas. Tais iniciativas são identificadas como instrumentos do progresso e como parte da necessidade de reverter a crise de acumulação do capital.

O nexo entre crise e progresso que, neste momento, define uma nova configuração do Estado e das classes sociais se sustenta nos argumentos de que não há alternativa para o desemprego sem que haja um forte investimento na qualificação profissional. As ideias de progresso, empregabilidade, empreendedorismo, cidadania, perpassam todo o discurso de enfrentamento desta problemática.

É neste sentido que, neste artigo, construímos nossa argumentação para mostrar como, numa conjuntura de crise, o capital lança mão de uma política potencializadora de consensos para responder à sua crise. A política de qualificação profissional se torna, então, um desafio não só para trabalhadores, mas também para os profissionais que atuam na sua execução, como os assistentes sociais, na medida em que ela tanto pode atender às necessidades do trabalho como pode servir aos interesses do capital, via mercado, refuncionalizando as reinvindicações sindicais e favorecendo a incorporação acrítica do discurso dominante que a sustenta.

\section{Crise capitalista e qualificação profissional: determinantes e nexos}

Na história e na literatura recentes sobre a crise contemporânea e as respostas engendradas pelo capital a esta crise, a ideia do "progresso" 2 é difundida como uma tendência que universaliza as relações capitalistas e cria as bases materiais para a reprodução das classes sociais. Portadora de uma ideologia que objetiva a perenização de tais relações, esta ideia nos parece ser o fio condutor que sustenta um conjunto de mudanças que vêm sendo empreendidas, em nível mundial, nas esferas da economia e da política, em um permanente movimento de reestruturação da sua existência histórica. Movimento este, diga-se de passagem, onde o capital procura,

\footnotetext{
"Este argumento é tratado ao longo das discussões contidas na tese de doutorado da autora "Qualificação dos trabalhadores e estratégia de hegemonia: o embate de projetos classistas" (AMARAL, 2005).

2 Segundo Wood (2003, p.129), a discussão sobre o "progresso" está associada ao Iluminismo e apresenta-se sob a forma de duas ideias distintas, mas relacionadas entre si. Uma dessas ideias diz respeito à questão do aperfeiçoamento humano, compreendido como fenômeno político-cultural, de ascensão da liberdade e da razão. A outra ideia está relacionada a um tipo de materialismo que via a história como uma evolução dos "modos de subsistência" ou o amadurecimento do último estágio, o mais perfeito, da "sociedade comercial".
} 
incessantemente, formas inovadoras de autovalorização, utilizando-se cada vez menos do trabalho vivo, base de todo processo capitalista de acumulação.

Os argumentos sobre a crise da sociedade do trabalho e, consequentemente, o deslocamento da sua centralidade constituíram-se em um arsenal teórico bastante utilizado pelos intelectuais, desde o final dos passados anos 1960 até os dias atuais, para explicar a crise contemporânea. No entanto, a difusão dessa análise nos meios acadêmico, intelectual e profissional não foi capaz de demonstrar a "desnecessidade" do trabalho vivo ou a sua eliminação dos processos de produção. Dito de outro modo: tais argumentos puderam exercer sua influência, principalmente entre as classes subalternas, mas não conseguiram alterar o real, onde a permanência do trabalho - em qualquer que seja sua forma - manifesta, consciente ou inconscientemente, seu antagonismo. A despeito da inserção que estas posições alcançaram, o que de fato se pôde notar foi a incorporação do trabalho vivo sob a forma de trabalho morto, cujo suporte material é a tecnologia, forma particular do trabalho intelectual. ${ }^{3}$

É contra essa perspectiva de análise da crise capitalista que nos posicionamos e tentamos apreender os nexos entre a crise, os determinantes dessa crise e nossa problemática de estudo, a qualificação profissional.

Indicativa de um processo que revela as contradições e antagonismos que são peculiares à formação especificamente capitalista, podemos afirmar que esta crise não é nova. Ela reflete um conjunto de determinantes que vinham sendo questionados desde o período do segundo pós-guerra, determinantes estes que dizem respeito às relações estabelecidas entre as formas de o capital expropriar, em larga escala, o sobretrabalho e as lutas de classes que se desenvolvem a partir dos modos de propriedade que as relações de produção capitalista encerram.

Esta forma de o capital operar na realidade e de superar suas contradições internas expressa uma crise orgânica, como já afirmamos, uma crise afeta à totalidade da formação social, às relações entre economia e política; entre os movimentos tendenciais aos quais está submetida a produção material, que são os pilares da dinâmica capitalista e as relações políticas das classes sociais, elementos fundamentais à constituição do modo de produção capitalista, os quais são modificados à medida que os grupos dominantes impõem formas renovadas de intervenção na sociedade para manter, ao mesmo tempo, o seu domínio no núcleo decisivo da atividade econômica e nas formas de subalternidade política dos trabalhadores.

O pressuposto da nossa investigação a respeito da crise capitalista, como já afirmamos anteriormente, é aquele que a qualifica como uma crise orgânica, assim concebida por Gramsci (2000) porque é expressão

3 Esta é a posição assumida, entre outros autores, por Offe (1989), Kurz (1992), Gorz (2003), Habermas (1987). 
dos antagonismos que, ao se originarem no ambiente econômico, transitam para o ambiente político. Portanto, ao se ampliar para o campo das relações políticas, ideológicas, culturais, seus efeitos atingem a essência das relações de classe, transformando o conteúdo das lutas sociais, substituindo-as por lutas de interesse. ${ }^{4}$

Neste movimento, as classes dominantes tentam neutralizar os antagonismos classistas e impedem o surgimento de crises que possam colocar em xeque o funcionamento do modo de produção capitalista. Aqui as contradições do sistema não só afloram no sentido de revelar os entraves ao processo de acumulação como permitem dizer que esse modo de produção é obrigado a mudar suas táticas de curto prazo, para ser capaz de legitimar-se frente às forças sociais que pretende dominar.

Em outros termos, a crise à qual nos referimos exige um processo permanente de transformação tanto do padrão de acumulação de capital, aí compreendido o papel das forças produtivas, como das estratégias de dominação que conformam os aparelhos da hegemonia burguesa.

É o movimento de permanente superação e reposição de suas contradições que determina a crise do capital e que engendra estratégias de reestruturação que viabilizam a sua recomposição material e política. Se entendermos que o processo de reprodução das relações de produção é, ao mesmo tempo, o processo de reprodução das relações de classes, podemos pensar que o que está em causa é a negação de formas antagônicas entre as classes sociais e o modo como o capital tenta naturalizá-las.

É por essa razão que se impõe o empreendimento de iniciativas que coloquem capital e trabalho lado a lado, numa mesma unidade ideológica, que traduz o projeto da classe burguesa. Tal unidade é dada pela exigência de se obter a maior produtividade do trabalho através da introdução de mudanças na gestão do trabalho e no desenvolvimento pleno das forças produtivas, tratadas seccionadamente como revolução tecnológica.

O conjunto dessas mudanças tem viabilizado formas "modernas" de gestão e o seu caráter integrador e participativo parece conformar um trabalhador autônomo, criativo, livre da férrea disciplina que caracterizou o período taylorista-fordista. Na realidade, essa aparência necessária revela o movimento histórico do capital para tornar-se uma relação social autônoma frente ao trabalho, cujas contradições são ocultadas em favor dos benefícios obtidos com o incremento da ciência e da tecnologia e das supostas possibilidades emancipatórias que estão subjacentes a esse par conceitual.

\footnotetext{
${ }^{4}$ Essa discussão é desenvolvida nos estudos de Braga (2003), que ao se referir às mudanças operadas pelo capital e seus efeitos sobre as práticas classistas, apresenta o deslocamento das lutas de classe pelo processo de negociação, o conflito pelo consenso. Na perspectiva de algumas correntes teóricas, como a regulacionista, as lutas dos trabalhadores não são mais lutas de classe, mas, de classificação.
} 
Deriva desse movimento a ideia de que essas radicais transformações no processo de trabalho exigem um novo trabalhador, mais especializado, mais comprometido com os objetivos empresariais e apto para dar conta das novas necessidades de acumulação do capital. Isso significa total disponibilidade do trabalhador para o processo produtivo sob o comando estrito do capital e sugere uma naturalização das estruturas de exploração, agora mediadas por técnicas participativas, colaboracionistas, que envolvem os trabalhadores e sua subjetividade, no sentido da capacidade antagônica dos mesmos serem transformadas em horizonte e possibilidade de conciliação de interesses.

O movimento de mundialização que se manifesta com maior visibilidade a partir dos anos 80 e se aprofunda nos anos 90 do século passado - com a sua nova face de financeirização ${ }^{5}$ da economia - é expressão de uma crise global por que passa o capitalismo contemporâneo. Em torno dessa forma assumida pelo capital ${ }^{6}$, o Estado capitalista, como expressão própria de um grupo cuja tarefa é criar as condições favoráveis de expansão plena desse grupo (GRAMSCI, 2000), tem-se colocado, cada vez mais, como garantidor dos ganhos privados e vem pondo em marcha uma completa redefinição das suas funções para atender aos objetivos de recomposição das taxas de lucro capitalistas. Esse processo, que muitos autores tratam como sendo de "globalização", tem como pilares de sustentação a abertura e desregulamentação dos mercados, a privatização de serviços públicos, a flexibilização das relações entre capital e trabalho. Ou seja, envolve um conjunto de sujeitos (classes, suas formas organizacionais, etc.) e esferas da vida social. Ele diz respeito às formas históricas de embate que capital e trabalho utilizam para defender seus projetos de classe.

Essa mudança de rota que o capitalismo empreende na sua base de dominação requer iniciativas e mecanismos que modifiquem não somente a base material, mas também as condições de reprodução social e as ideologias até então vigentes, vale dizer, a racionalidade burguesa com suas formas de institucionalização. Esta afirmação, de cunho metodológico, tem por finalidade combater uma visão segmentada do social e afirmar o primado da categoria da totalidade. Assim, afastamos a possibilidade de pensarmos "dedutivamente" o movimento do real como simples tradução de um vago "econômico" ou pensar a ideologia como reflexo daquele.

\footnotetext{
${ }^{5}$ Todo esse debate sobre o movimento de mundialização e financeirização da economia capitalista contemporânea está brilhantemente colocada nos estudos de François Chesnais: "A mundialização do capital" (1996) e "A mundialização financeira" (1998).

${ }^{6}$ Husson (1996, p.100) ressalta o risco de avaliações superficiais que reduzem a compreensão da crise enquanto uma preferência do capital pelas aplicações especulativas do capital em detrimento do investimento na produção. Tal compreensão, segundo o autor, pode conduzir a um certo fetichismo das finanças. E lembra bem que, quando se fala dos juros enquanto forma de rendimentos não produtiva, está se tratando, na realidade, de uma das formas de mais-valia.
} 
Nesse cenário, a reestruturação produtiva e o neoliberalismo funcionam como artífices da reformulação de um projeto societário, em que as ideias de construção do socialismo e a função distributivista do Estado de Bem-Estar já não mais participam da agenda dominante da moderna sociedade. É por isso que, para o capitalismo, se faz necessário "destruir" as bases sobre as quais se edificaram os valores da razão moderna e impingir um outro modelo, que também pretenda ser universal, mas fundado em princípios, que não mais os da razão iluminista, tratada por Gramsci como uma "magnífica revolução", criadora de "uma consciência unitária, uma internacional espiritual burguesa". (2004, p.59).

O que este momento atual nos indica é que está em curso uma estratégia de construção de hegemonia, cujos vetores vêm sendo traçados no interior da luta concreta das classes em presença, isto é, nas singularidades das suas práticas, das suas subjetividades e no embate dos projetos que as representam. Tanto é assim que grande parte dos formuladores de propostas vinculados às classes dirigentes procura adentrar no campo do adversário e transformar os projetos que lhes são próprios em interesses gerais, como se não mais existissem diferenças na sociedade, na natureza e nos conteúdos dos seus interesses. Esta intervenção ideológica, na qual os dirigentes e seus intermediários conseguem fazer o trabalho migrar para o outro campo, vem sendo possível, em larga medida, pela intervenção de intelectuais que estiveram no chamado "campo da esquerda" - entre outros, os regulacionistas e ex-maoístas - e que, durante muitos anos, se apropriaram da ideologia e das formas de fazer política dos subalternos e a reconstruíram na perspectiva de adesão à racionalidade capitalista.

\section{As diretrizes neoliberais dos programas educacionais e os sindicatos}

No contexto da reestruturação produtiva, o capital lança mão de elementos novos, mas também recupera formas combinadas de domínio e exploração. Mais-valia absoluta e mais-valia relativa coexistem em um mesmo momento da produção sob o comando da mais-valia relativa. Da mesma forma, podemos pensar nas qualificações dos trabalhadores: se em determinados ramos industriais as exigências são cada vez mais complexas, em face da introdução, no processo produtivo, de máquinas e equipamentos que requerem novos procedimentos técnicos, em outros, a "desqualificação" é condição basilar para a acumulação ampliada. Já no final do século passado, Salama (1998, p.246-247) afirmara:

A introdução de novas técnicas, muitas vezes importadas, serve de suporte para a flexibilização. As mudanças na gestão do trabalho permitem uma valorização do capital. A financeirização e a in- 
suficiência de investimento, que dele resulta, a pressão externa mais forte, já que a obsolescência da indústria é freqüente e a retirada do Estado evidente, conduzem a uma valorização insuficiente do capital. Segue-se a isso a adoção da organização flexível, mas também da sua caricatura.

Particularmente em relação à educação, as diretrizes do Banco Mundial são indicativas de um modelo que conduz a uma ampla reforma em relação às políticas vigentes nos países, especialmente naqueles chamados "emergentes". Sobre isto, é fundamental a análise do período PSDBPT, seus projetos, suas "reformas". Elas passam por definições que envolvem discussões sobre o monopólio da ciência e da tecnologia, sobre as novas requisições em termos das qualificações, sobre o papel da sociedade civil, entre outras.

Trata-se de um receituário que vai além do chamado Consenso de Washington, cuja expressividade é alcançada à medida que as reformas vão se ampliando com a intervenção ativa do Estado, que passa a dar suporte para que novos espaços de acumulação sejam criados na esfera da economia, redimensionando, inclusive, a gestão, o financiamento e o controle social dos recursos públicos.

Em linhas gerais, o modelo preconizado pelo Banco Mundial para a ciência e tecnologia implica em relações de dependência cada vez mais estreitas com os países centrais. Para a maioria dos países, o lugar reservado à tecnologia é o de consumidor de pacotes tecnológicos ou, quando muito, de executor de processos controlados pelos países que mantêm a matriz do conhecimento científico, numa clara posição de que a estratégia não é a de socialização da ciência e da tecnologia, das descobertas científicas, mas de uma divisão internacional de trabalho ${ }^{7}$ que tenha como eixo a centralização do processo produtivo mundial nas mãos de poucos países e a definição de quais parcelas da sociedade podem, ou não, se integrar à economia mundial, nessa nova fase de acumulação. Para que isso ocorra, a estratégia das grandes empresas é potencializar a produtividade do trabalho, utilizando-se, para tal, a equação força de trabalho abundante e pagamento de baixos salários. ${ }^{8}$

Sob esse ângulo, Husson analisa que

a economia mundial surge como um filão quase infinito de força de trabalho a baixos preços: os capitais movem-se de um lado para o outro, e vão fixar-se num local que Ihes pareça atrativo; decidem instalar-se ou, pelo contrário, aventurar-se um pouco mais longe. Mas,

\footnotetext{
7 Caso típico é o "projeto genoma".

${ }^{8}$ Embora não seja o tema deste trabalho, as modificações acima indicadas também atuam na área das ciências sociais. Essa mutação altera a própria base do que se pode pensar, pois, ao definir uma "verdade" ela pretende jogar na lata do lixo da História centenas de anos de elaboração.
} 
sua vocação não é cobrir o terreno todo, nem para aí transplantar todas as tecnologias, por razões simultaneamente de escala de produção mas também de vontade de controlo. (1996, p.108).

Na periferia do capitalismo, este modelo responde por condições desiguais de acesso à educação, às tecnologias, às condições de salário, emprego e condições de vida. Isto porque os organismos internacionais e seus intelectuais que buscam consolidar a nova forma histórica do capitalismo definem as diretrizes educacionais para esses países tendo como base a reorganização da divisão internacional do trabalho e as possibilidades de maior rentabilidade do capital nesse campo. Daí decorrem as orientações que incentivam os interesses de mercantilização do setor educacional, tendo-se como ilustrativo o crescimento vertiginoso das universidades privadas $^{9}$ e a consequente degradação das universidades públicas. ${ }^{10}$

No Brasil, o processo de incorporação de tais diretrizes se constitui em prioridade absoluta e exemplar na América Latina. Afinal de contas, o argumento de que somos o último país "emergente" do continente a aderir ao programa dos teóricos do capital resultou em medidas que visavam afastar o Estado da produção de conhecimento estratégico para o país, malgrado as resistências às mudanças propostas, sempre muito acirradas. Vale destacar que tais resistências ocuparam a pauta dos setores mais organizados da educação, tensionados e mediados pelos argumentos da democratização do ensino, da cidadania e da possibilidade de ampliação da sociedade civil nas decisões governamentais.

Sob esse ângulo, o debate sobre a educação é "aparentemente"11 ampliado a toda sociedade, agora não mais sob a vigilância e a crítica das representações dos sindicatos de classe, tornados personae non gratae, porque "desobedientes" em relação ao governo, mas com o comando de protagonistas que trabalham na perspectiva de adotar premissas gerenciais e critérios de eficiência e eficácia gerencial nas ações governamentais, a exemplo das "avaliações" produtivistas, no caso das universidades.

\footnotetext{
${ }^{9}$ Conforme dados do Censo de Educação Superior, publicado pelo INEP, em 2011, o setor privado responde por $74 \%$ das vagas oferecidas no ensino superior e $26 \%$ das vagas são ofertadas pelo setor público, no ensino de graduação. Apenas $12 \%$ das duas mil trezentos e sessenta e cinco instituições do ensino superior do país são públicas - MINISTÉRIO DA EDUCAÇÃO/ INEP. Censo de Educação do Ensino Superior (BRASIL, 2011).

10 Em 2011, sob a gestão de Dilma Roussef, foi anunciado um corte no orçamento federal da União da ordem de R \$50,1 bilhões. A educação sofreu um corte de R\$ 3,1 bilhões, sendo o terceiro ministério mais afetado em termos de valores nominais (Nota de Redução de Despesas. Ministério da Fazenda/Ministério do Planejamento, 2011). Ao mesmo tempo, também foi anunciado que as 61 universidades federais e os institutos tecnológicos passariam por auditorias para revisão dos gastos (SBPC, 2011).

11 Sobre isso, ver o procedimento das "audiências públicas" que desde o governo FHC estão implantadas sob a pressão da chamada sociedade civil e que no governo Lula se mantiveram enquanto "espaço de discussão" de temas de interesse público. Longe do grande público, com "representações da sociedade" eleitas pelo governo (e não pela sociedade), sem contraditório e com um conjunto de perguntas que os "representantes" deveriam responder, sem qualquer consulta ao seu teórico corpo de origem.
} 
No entanto, o dado novo nessas iniciativas estimuladas pelos organismos internacionais é a participação ativa de dirigentes sindicais pró-governo na elaboração e execução dos programas educacionais e, em particular, naquele que é nosso objeto de estudo, nos de qualificação profissional e a concepção que eles - os sindicatos - assumiram como sua: a de que estas medidas resolveriam o problema do desemprego, compreendido, no momento atual, como um problema de qualificação. Esta é uma questão central que atravessa as discussões sindicais durante os primeiros anos de vigência dos programas.

Tais iniciativas, na aparência, não só representam um investimento positivo para o conjunto dos trabalhadores e para a sociedade em geral, mas estimulam o acesso aos meios educacionais, que os sindicatos sempre reclamaram, nas suas pautas de reivindicação. Ao mesmo tempo, podem significar uma forma concreta de mobilidade social em uma sociedade em que os valores da educação serviram, em conjunturas históricas determinadas, para reforçar a ideia de nacionalismo, de soberania e de desenvolvimento. Isto é, educação vinculada à ideia de progresso. Tudo isso, obviamente, pensado abstratamente em referência às classes, suas contradições e antagonismos.

Desse modo, o tratamento teórico-prático dado à qualificação profissional passa a ser uma questão estratégica no interior dos sindicatos e na chamada sociedade civil. Mobilizadores de interesses genéricos e solidários e, ao mesmo tempo, individuais, porque trabalhados sempre na perspectiva de uma apropriação individual de competências para manutenção e aumento da empregabilidade, os formuladores dos programas de qualificação / requalificação têm conseguido construir, na sociedade, um ideário que afirma "esperanças" em torno de uma economia que se movimenta para atender às necessidades de uma acumulação de capital cada vez maior e onde a seletividade e a desigualdade se constituem em princípios imanentes de funcionamento da dinâmica capitalista. Esperanças cuja concretização é, no mínimo, de pouca possibilidade de efetivação.

\section{Paradoxos da política de qualificação/requalificação profissional no Brasil}

As informações contidas nos estudos já sinalizados revelam que o empresariado brasileiro investiu com muito vigor na implementação das inovações e na qualificação da força de trabalho para responder a sistemas tecnológicos específicos que requeriam maiores habilidades cognitivas para coordenar processos de trabalho. Esse período, que muitos estudiosos chamam de "especialização flexível", é rico em interpretações sobre a passagem de um sistema de produção em massa para o de uma flexibilidade do pro- 
cesso produtivo, orientado para mercados segmentados como possibilidade, mas não como tendência dominante.

Embora não trabalhemos com a classificação categorial acima, é importante ter em conta que a discussão central que se coloca, neste momento atual do capitalismo, é relativa à retomada ou não do controle do processo de trabalho, haja vista as possibilidades abertas de os trabalhadores participarem dos processos decisórios da empresa bem como da concepção do seu trabalho, caracterizando uma colaboração com os objetivos capitalistas e, consequentemente, uma convergência de interesses entre capital e trabalho.

Este era o foco dos processos e práticas desenvolvidos, que nos anos 1980 em análise, transformaram as empresas em laboratórios de experiências, em grande medida legitimadas pelos trabalhadores, posto que previam eleições diretas para gerências, acesso e democratização das informações, criação de representações de trabalhadores junto aos órgãos decisórios das empresas, comissões internas inteiramente eleitas e representadas pelos trabalhadores, entre outras conquistas.

É somente em meados daquela década que a problemática da qualificação começa a adquirir contornos mais precisos frente à dinâmica econômica. Isto porque as mudanças requeridas no âmbito da produção encerram exigências de qualificação que respondam às necessidades de manuseio de novas máquinas e tecnologias, de tomada de iniciativa dos trabalhadores para resolver problemas, de realização de trabalho em equipe, para que a produção seja compreendida como esforço coletivo de trabaIhadores. "Iniciativa" no interior dos interesses do capital, é claro. Isto significa estar atento e pronto para a execução de tarefas heterônomas. Iniciativa supõe autonomia. A essas requisições, correspondem, na visão das lideranças empresariais, formas de se agregar novas qualificações cognitivas ao trabalho, de conferir maior autonomia para decisões no processo produtivo e de superar a visão tradicional entre concepção e execução do trabalho.

Por essas razões, o empresariado vai exigir do Estado iniciativas que ampliem o acesso à educação aos trabalhadores bem como assuma responsabilidades que aumentem a capacidade dos mesmos para estarem disponíveis ao processo de produção. Ou seja, a necessidade de um projeto educacional sob o comando do Estado deve estar vinculada às exigências de competitividade e produtividade das empresas. O que significa dizer que a qualificação profissional foi e é uma resposta do capital e do Estado que, juntos, transformaram processos instrumentais restritos e parciais em uma política de educação. Aqui vale toda sorte de qualificação: ensino à distância, cursos sequenciais, modulares, de curta duração, profissionalizantes, virtuais, entre outras modalidades.

Não obstante uma relativa melhoria nas condições de conhecimento (entendido na literatura e na prática capitalista como qualificação) de alguns profissionais, a realidade dos enfocados anos 1990 mostrou que 
tais condições foram restritas a determinados segmentos de trabalhadores, particularmente àqueles localizados nos setores mais dinâmicos da economia, cujas condições de concorrência internacional eram maiores. ${ }^{12}$

As pesquisas realizadas neste período indicam que a problemática da qualificação mostrava-se sempre mediada pela questão do sistema educacional. Consequentemente, a discussão sobre as deficiências do complexo educacional brasileiro tornava-se recorrente. Responsabilizava-se comumente os trabalhadores e sua baixa escolaridade pelas resistências e dificuldades de adaptabilidade às "novas" formas produtivas.

Nos resultados expressos até meados da década, era possível inferir que apenas os trabalhadores mais escolarizados e, portanto, aqueles dedicados a operações mais complexas, eram estimulados ou tinham facilidade de incorporar as novas aprendizagens necessárias à produção segmentada, descentralizada, dita enxuta. Aos demais se oferecia o treinamento em serviço, caracterizado pela dimensão instrumental, prática, atributo das concepções tayloristas/fordistas de produção que continuavam a ser majoritárias.

Nessa conjuntura, é possível afirmar que, de modo geral, a relação entre reestruturação produtiva e qualificação profissional é, ainda, muito tímida, no sentido de que não se materializa automaticamente, em todas as empresas e níveis ocupacionais. Ou seja, são pontuais os exemplos das plantas fabris que, de forma generalizada, fizeram alterações simultâneas nas formas de produzir e de qualificar sua força de trabalho no sentido amplo, na direção de alargamento das potencialidades da mesma para interferir e decidir sobre o processo e a organização de trabalho.

Mais do que essa preocupação, o empresariado, que historicamente teve no "Sistema $\mathrm{S}^{\prime 13}$ sua base de apoio para treinar a força de trabalho, passou a responsabilizar o governo pela baixa escolaridade dos trabaIhadores e pela ausência de uma política geral de educação que desse conta das necessidades atuais e mais genéricas de formação do trabalhador. Vemos aqui um claro indício da necessidade do capital de "reformar" a educação em todos os níveis.

$\mathrm{Na}$ realidade, tais necessidades visam muito mais a formação de competências específicas para o trabalho, frente às novas exigências da produção, do que mesmo a construção de um complexo educacional que

\footnotetext{
12 As pesquisas coordenadas por Castro $(1995 ; 2004)$ e Carleial e Valle $(1997)$ expõem e aprofundam as relações entre os processos de qualificação e seus efeitos nos chamados setores de ponta da economia, altamente competitivos, como é o caso da cadeia químico-petroquímica. Também o trabalho de Castillo (1996) é bastante esclarecedor no sentido de discutir as relações entre automação e qualificação.

13 Em 2004, o governo criou um fórum constituído por representantes do governo, dos trabaIhadores e das empresas para propor uma reestruturação do chamado Sistema S (SESI, SENAI, SESC, SENAC e SEBRAE), que arrecada, anualmente, cerca de 8 bilhões, orçamento que, segundo o Tribunal de Contas da União, era quase três vezes superior ao que a Únião estava destinando para gastar com saneamento básico naquele ano. (FOLHA DE SÃO PAULO, 2004).
} 
trabalhe na perspectiva de uma qualificação cujo fundamento seja o domínio de conhecimentos e habilidades que permitam ao trabalhador interpretar, criticamente, e intervir, globalmente, nos processos sociais e históricos que se dão na sociedade e no seu trabalho.

Competências específicas, isto é, adestramento. Vale a pena explicitar que o capital sempre necessitou do trabalhador "treinado" para atender as suas necessidades. O que mudou foram as condições da produção que, em alguns setores da economia, passaram a exigir processos sofisticados em algumas tarefas que implicam uma maior escolaridade formal dos trabalhadores.

Por sua vez, esta dinâmica, calcada sob bases ideológicas neoliberais, impõe uma ruptura com qualquer tipo de conhecimento mais perene, cumulativo e processual. Pelo contrário, o momento atual propaga o fim da razão como elemento fundante e explicativo da realidade social e, como corolário desta afirmativa, o conhecimento que se propõe difere radicalmente deste reivindicado pela burguesia.

Assim, o espaço educativo se torna campo de críticas e proposições por parte do empresariado, levando-o a mobilizar todas as suas representações a empreender o esforço de intervir nos processos educacionais.

Também com muita ênfase, o empresariado invoca o aspecto de coesão social que esse processo de educação geral desencadeará, coletivamente, o qual reunirá, indistintamente, interesses os mais diversos possíveis. A ideia de "concertação" é vital para dar unidade às propostas em curso. Sob essa prática, exemplifica-se e difunde-se o sucesso que diversos países lograram com os processos educacionais desenvolvidos e, ao mesmo tempo, ocultam-se as diferentes posições que os educadores têm a respeito das reais necessidades educacionais das classes subalternas.

Nesse cenário, o que de fato importa é que a educação constituase em uma estratégia formadora para as necessidades do mercado, o que, aliás, os programas formativos, sob o comando do empresariado, historicamente fizeram. A diferença reside na atual configuração do mercado e nas exigências que este empresariado faz aos trabalhadores no sentido da sua cooperação, do seu envolvimento e da necessidade de responder aos apelos de colaboração de classes para superar uma determinada condição de subalternidade frente aos países desenvolvidos.

Ao fazer isso, parece-nos que os trabalhadores concordam, "voluntariamente" ou obrigados, em apagar as referências históricas balizadoras das suas lutas por uma educação de qualidade, para transformarem-se em "atores" - porque apenas representam - de um processo que não foi por eles construído, mas imposto por necessidades econômicas da burguesia que agora quer ampliar seu domínio e tentar construir sua hegemonia na totalidade da vida social.

As estratégias educacionais de formação dos trabalhadores foram implacáveis nesse propósito. Tanto o empresariado quanto os governos e 
as lideranças sindicais - Central Única dos Trabalhadores (CUT) e Força Sindical - uniram esforços para empreender ações de grande monta, cujas metas estavam sendo permanentemente monitoradas pelas recomendações das agências internacionais ${ }^{14}$. Modelos educacionais e processos formativos foram elaborados pelos intelectuais do capital com o objetivo de definir parâmetros e medidas de qualidade, de eficiência e de produtividade na escola, conforme os matizes que embasam a produção capitalista, na contemporaneidade $^{15}$. O que realmente se revela com esses critérios é uma crescente diferenciação na qualidade da formação, no acesso às informações e aos instrumentos por ela gerados e na falsa ideia de que todos serão beneficiados nesse processo, porque a educação é condição para as oportunidades que o mercado capitalista está demandando. Mercado capitalista este, diga-se de passagem, que é diferenciado, segmentado, heterogêneo e que, segundo Marx (1989), é sustentado na desigualdade e na transformação das relações sociais em coisas, condição inerente ao processo de valorização de capital.

A "sociedade do conhecimento" vem sendo propalada como a expressão, por excelência, das mudanças nas relações capitalistas contemporâneas. A partir dos seus supostos é que se pensa a construção de uma outra racionalidade burguesa. E são os intelectuais orgânicos que irão sistematizar os conteúdos dessa racionalidade proposta, transformando-os em projetos de classe.

O fundamento da sociedade do conhecimento é o de que o desenvolvimento de sistemas tecnológicos e de comunicação conduziria a formas renovadas de relação entre capital e trabalho. Nesse raciocínio, os conteúdos que o capitalismo requer dos trabalhadores - no momento atual teriam, no capital-conhecimento ou no capital-inteligência suas fontes mais determinadas. Estas novas determinações são, na realidade, a contraface das posições marxianas que reafirmam o trabalho como fonte de produção e reprodução do valor.

Segundo Prado, essa contraposição é explicitada a partir da afirmação de que

\footnotetext{
${ }^{14}$ Nos documentos do Ministério do Trabalho e Emprego (1995) são recorrentes as alusões que se fazem às metas que devem ser atingidas com os programas de qualificação e requalificação profissional. A proposta do governo federal estabelecia, em 1996, que a oferta de educação profissional permanente para qualificar ou requalificar, deveria ser de $20 \%$ da população economicamente ativa, a cada ano, pelo menos.

${ }^{15}$ Gentili vai se reportar ao documento da CEPAL-UNESCO, "Educação e conhecimento: eixo da transformação produtiva com eqüidade", para dizer que o modelo chileno é considerado pelas instituições como o mais adequado para resolver a questão da qualidade no campo educacional. "Somente há qualidade quando o mercado opera em todo e qualquer espaço de ação pedagógica, em todo e qualquer nível de decisão política, em todo e qualquer dos infinitos fragmentos em que se transformou aquilo que, uma vez, chamou-se 'escola pública'. (apud GENTILI, 1994, p.170-171).
} 
A força de trabalho, portadora de qualificações úteis para a empresa aparece, então, como um capital fixo; o trabalhador surge como detentor de capital humano. Em ambos os casos uma mesma mistificação se apresenta: o capital variável é identificado com o capital constante, fazendo com que o acréscimo de valor apareça como resultado do adiantamento de capital - ou seja, retorno a maior lucro - e não como mais-valia gerada pelo trabalho vivo. (2004, p.55).

\section{Ao que acrescenta:}

A força de trabalho comprada como tal pelo capitalista pelo seu preço de mercado aparece, agora, como propriedade virtual da empresa. De fato, ela é propriedade formal do trabalhador - ainda que, de fato, esteja permanentemente à disposição dos capitalistas como um todo, ou seja, da classe capitalista. (PRADO, 2004, p.55).

Todavia, sob a égide do capitalismo contemporâneo, as leituras que autores de diferentes matizes teóricos fazem acerca das chamadas "mutações do mundo do trabalho", a exemplo de Habermas, Gorz e, mais recentemente, Negri, Hardt, Lazaratto e outros, como Rifkin ${ }^{16}$, reafirmam e atribuem ao capital-conhecimento um papel fundamental que permite articular novas formas de acumulação. A centralidade do trabalho é substituída pela centralidade do conhecimento e a produção depende cada vez mais de um trabalho vivo intelectualizado e pautado na ação comunicativa.

A nosso ver, estes são os valores e atributos que pretendem orientar a moderna produção capitalista, os quais são perseguidos pelas empresas brasileiras, na tentativa de adequar as tendências mundiais da produção às particularidades do desenvolvimento econômico do país. Tudo se passa como se, dadas tais condições de acesso ao conhecimento, automaticamente o Brasil entrasse no rol dos países com vantagens competitivas em níveis iguais àqueles que já alcançaram um grau superior de desenvolvimento das forças produtivas.

Ademais, é preciso deixar claro que a opção de desenvolvimento adotada pelas personificações do capital neste país priorizou, historicamente, uma profunda dependência externa em relação aos recursos, uma relação perversa no que tange às relações entre capital - trabalho e a

\footnotetext{
${ }_{15}$ Gentili vai se reportar ao documento da CEPAL-UNESCO, "Educação e conhecimento: eixo da transformação produtiva com eqüidade", para dizer que o modelo chileno é considerado pelas instituições como o mais adequado para resolver a questão da qualidade no campo educacional. "Somente há qualidade quando o mercado opera em todo e qualquer espaço de ação pedagógica, em todo e qualquer nível de decisão política, em todo e qualquer dos infinitos fragmentos em que se transformou aquilo que, uma vez, chamou-se 'escola pública'. (apud GENTILI, 1994, p.170-171).

16 As idéias de Rifkin (1995), autor do best-seller "O fim dos empregos", alcançaram grande audiência no meio acadêmico e na mídia, principalmente por vincular o debate do Terceiro Setor com a inevitabilidade do fim do emprego.
} 
manutenção de uma força de trabalho desqualificada, mais submissa e, consequentemente, mais explorada.

Contudo, o que fica patente é que este argumento sobre o conhecimento que mobiliza inúmeras iniciativas viabilizadas tanto pelo empresariado, pelo governo, quanto pelos representantes dos trabalhadores, ao mesmo tempo em que é colocado como condição de valorização da força de trabalho, também funciona como estratégia de desenvolvimento capitalista que valoriza mais e mais o capital.

Afirmamos que esta estratégia nada mais é que um fetiche, posto que oculta uma relação essencial que é a de tratar a ciência, a tecnologia e o conhecimento que elas geram como formas de reatualizar a subsunção real do trabalho ao capital. Esta, de fato, é a revolução nos meios e modos de produção de que falam aqueles autores. O capital conseguiu avançar nas suas modalidades de extração de sobretrabalho, o que não significou eliminar trabalho vivo. Mais uma vez, na história do desenvolvimento capitalista, tenta-se apropriar do saber operário, agora mediado por novas condições. Trata-se, repetimos, da forma mais avançada - do ponto de vista capitalista, é claro - da subsunção real do trabalho ao capital.

\section{Os desafios do Serviço Social diante dos programas de qualificação profissional}

Para o Serviço Social, a demanda para atuar nos processos de qualificação profissional se apresenta sob o argumento de que o acesso a processos educacionais e a preparação para o mundo produtivo são a chave para a autonomia e a emancipação dos "excluídos". É possível perceber que a grande maioria dos programas sociais dos últimos governos do Brasil, incorpora, nas suas diretrizes, ações e conteúdos voltados à realização de qualificação profissional.

Tais iniciativas, segundo os formuladores desses programas, respondem pela possibilidade de inclusão social ou inclusão produtiva de um imenso público, que, na verdade, vem sendo "formado" para tornar-se "apto" a um mercado de trabalho que não comporta amplamente tal inserção. Aliás, a ideia é de que se mantenha uma força de trabalho para a realização de trabalho simples qualificada e, pelo mesmo movimento, que se invista em conteúdos atitudinais/comportamentais que difundam o empreendedorismo e o auto negócio como parte das estratégias da nova configuração do mercado de trabalho e do consumo.

A ideia, portanto, é criar uma nova cultura de trabalho, um novo ethos na economia periférica, onde o direito à renda substitui o direito ao trabalho. É nesse ambiente que os assistentes sociais são convocados para mobilizar os sujeitos para participar dos cursos, sugerir os tipos de curso a serem desenvolvidos, cadastrar o público da qualificação, monitorar e acompanhar as dificuldades encontradas pelos participantes, realizar con- 
tatos com instituições promotoras dos cursos e seus "facilitadores" , dentre outras atividades.

Os desafios profissionais diante dessa demanda permanecem sendo os desafios de uma profissão que se depara, na sociedade contemporânea, com processos sociais cujas bases, do ponto de vista da gestão, das condições, da proteção e das relações de trabalho, não encontram mais amparo nas formas protegidas e duradouras de vínculos. Nesse contexto, o auto negócio, o empreendedorismo, a flexibilização são estimulados, tornados naturais a informalidade, a flexibilização e as formas precárias de trabalho.

A meu ver, o Serviço Social, ao trabalhar com esta realidade, não pode sucumbir ao discurso dominante de que a qualificação profissional é meio e condição para a inclusão social ou mesmo a principal alternativa para a cidadania e emancipação dos sujeitos sociais no cenário atual. Aqui, nossa compreensão é que precisamos adensar nossa problematização e crítica sobre os referidos programas, desvendando seu significado e funcionalidade frente à dinâmica produtiva e às propostas de combate à pobreza e, tendo clareza de que, ao transformar uma demanda institucional em demanda profissional, devemos persistir no caminho de trabalhar as contradições presentes no processo, exercitando a crítica teórica e política que orienta tais programas e, sobretudo, articular estratégias coletivas que reponham o tema da qualificação profissional nos patamares da discussão sobre os processos educacionais mais amplos na sociedade brasileira, na defesa de uma educação de qualidade referenciada nas reais necessidades dos seus trabalhadores.

\section{Considerações Finais}

A política de qualificação/requalificação profissional se inscreve no conjunto das políticas voltadas para o emprego e geração de renda. Constitui, portanto, uma unidade contraditória mediada, também, pela política de educação, sendo, ao mesmo tempo, objeto de necessidades tanto do trabalho como do capital. Ainda que possamos pensar que estas necessidades do trabalho não são atendidas independentemente das do capital, é necessário afirmar que, na dinâmica capitalista contemporânea, elas respondem por adequar, como diria Barcelona (1994), o governo da economia e o governo das massas.

Em síntese: na aparência, a política de qualificação/requalificação profissional integra as necessidades do trabalho, mas, termina sendo incorporada como sendo necessidade de todos, o que não anula o uso que o capital faz dela, através dos seus prepostos, já que, sob o comando do capital, a transformação de uma mercadoria pode atender a necessidades que estão postas. Daí afirmarmos que aquela política seja objeto de iniciativas de mercantilização, entre outras razões, pelo fato de tornar-se fator de mobilidade social, legitimando, assim, o processo de acumulação. 
Nesse contexto, criam-se campos de acumulação de capital cada vez mais amplos e aprofunda-se a lógica de que a educação deve ser compreendida como uma mercadoria qualquer; os organismos internacionais investem no discurso da democratização dos recursos públicos, do controle social, da transparência no uso dos recursos. Aliás, diga-se de passagem, aspectos historicamente defendidos pelos trabalhadores, em especial os vinculados ao movimento dos trabalhadores da educação.

Ao conjunto de proposições que identificam qualificação com educação e transformam esse processo em fator de mobilidade social, procura-se associar a oportunidade de os trabalhadores adquirirem maior conhecimento. E isso, seguramente, está presente nos argumentos dos trabalhadores quando participam dos programas de qualificação e requalificação profissional - com as possibilidades de inserção no mercado -, o que, do nosso ponto de vista, significa uma resposta defensiva, por parte dos trabalhadores e das suas representações, à estratégia da empregabilidade, promovida pelo discurso do empresariado e do Estado, com o aval dos organismos internacionais. Estado esse, aliás, que tem a função de organizar o consenso na sociedade e fortalecer uma posição de classe que é, essencialmente, a posição dominante.

Embora concordemos com o princípio de que o acesso à educação, realizado mediante processos individuais moleculares ou de lutas políticas pela organização da cultura ao nível de massa (MANACORDA, 1990) é importante para formar o homem coletivo (GRAMSCI, 2000), devemos realçar que, nos termos em que a educação vem sendo tratada, ela não se transforma em objeto de criação de uma outra sociabilidade que seja capaz de transcender às necessidades atuais do capitalismo contemporâneo.

É, principalmente, pela via do discurso da consolidação da cidadania e da sociedade do conhecimento que a reforma na educação, proposta pelas agências multilaterais, parece ter concretude na sociedade. Pode-se dizer que cidadania e democracia caminham juntas e constituem uma unidade, comum a todas as forças sociais em presença. Não há espaço para classes ou antagonismos. O que se pretende é "suprimir o político, no sentido amplo da dinâmica entre o exercício do poder e a resistência a ele". (MARCUSE apud JESSOP, 2005, p.9).

O pacto social encontra aqui o seu reino. A democratização dos fundos públicos e a participação da sociedade nas decisões do Estado se transformam no baluarte dos argumentos indiferenciados de empresários, governo e trabalhadores.

São esses elementos orientadores de uma sociedade civil colaboradora, ativa e participativa que se adequam à fase atual do capitalismo e do Estado, os quais, na compreensão dos intelectuais da burguesia, podem ser potencializados, posto que não entram em contradição com a dinâmica da acumulação. Pelo contrário: hoje, a emulação aos processos dinâmicos que essa sociedade civil empreende, integra, pacificamente, a estratégia 


\section{ReVistg all paUtg}

\} A QUALIFICAÇÃO PROFISSIONAL DOS TRABALHADORES NA PERSPECTIVA - AMARAL, A. S. \}

dos capitalistas - a exemplo das iniciativas do terceiro setor, do voluntariado, da responsabilidade social - e transforma a existência real do que é classista, nessa sociedade civil, em uma nova forma de existência social, que, agora, constitui parte da busca da hegemonia das classes dominantes na sociedade.

Ademais, como parte constitutiva desse processo, é preciso destacar que, ao converter a educação em qualificação e requalificação profissional e, portanto, em potencial objeto de mercantilização, longe de se apontar para a ruptura com a exploração - como pretendem mostrar os apologetas da sociedade do conhecimento - o que se constata é que as reais necessidades de educação dos trabalhadores são absorvidas pelo capital, através da apropriação do tempo de vida do trabalhador, do seu conhecimento e das suas qualificações adquiridas no seu trabalho. 


\section{Referências}

AMARAL, A. Qualificação dos trabalhadores e estratégia de hegemonia: o embate de projetos classistas. Tese (Doutorado em Serviço Social) - Escola de Serviço Social/ UFRJ. Rio de Janeiro, 2005.

BARCELONA, P. Diario Politico. I/ vento di destra e le ragioni della sinistra. DataNews, Roma, 1994.

BONELLI, R. A reestruturação industrial brasileira nos anos 90: reação empresarial ao mercado de trabalho. In: BRASIL. MINISTÉRIO DO TRABALHO E EMPREGO. Abertura e ajuste no mercado de trabalho no Brasil. Rio de Janeiro: Editora 34, 1999.

BRAGA, R. A nostalgia do fordismo: modernização e crise na teoria da sociedade salarial. São Paulo, Xamã, 2003.

BRASIL. MINISTÉRIO DO TRABALHO. Questões críticas da educação brasileira: consolidação de propostas e subsídios para ações nas áreas da tecnologia e da qualidade. Brasília: MTb/PACTI/PBQP, 1995

. MINISTÉRIO DA FAZENDA. MINISTÉRIO DO PLANEJAMENTO. Nota: Redução de Despesas. 28 de fevereiro de 2011. Disponível em: <http:/ /www.planejamento.gov.br>. Acesso em: 01 mar. 2011.

. MINISTÉRIO DA EDUCAÇÃO/INEP. Resultados do Censo da Educação Superior 2011. Disponível em: <http://www.portal.mec.gov.br>. Acesso em: 26 out. 2012.

CARLEIAL, L.; VALLE, R. (Orgs.) Reestruturação produtiva e mercado de trabalho no Brasil. São Paulo: Hucitec, 1997.

CASTILLO, N. I. Automação e qualificação do trabalho: elementos para um enfoque dialético: Dissertação (Mestrado) - Instituto de Geociências. Programa de pós-graduação em Política Científica e Tecnologia. Universidade Estadual de Campinas. 1996

CASTRO, N. A máquina e o equilibrista: inovação na indústria brasileira. São Paulo, Paz e Terra, 1995.

- Caminhos cruzados: estratégias de empresas e trajetórias de trabaIhadores. São Paulo, Editora 34, 2004

CHESNAIS, F. (Coord.). A mundialização financeira: gênese, custos e riscos. São Paulo: Xamã, 1998.

- A mundialização do capital. São Paulo, Xamã, 1996.

FOLHA DE SÃO PAULO. "Governo quer ampliar poder no Sistema S". FoIha de São Paulo. Caderno Mercado. São Paulo, 26 set. 2004. 


\section{ReVista all paUtg}

\} A QUALIFICAÇÃO PROFISSIONAL DOS TRABALHADORES NA PERSPECTIVA - AMARAL, A. S. \}

GENTILI, P.A.A. O discurso da 'qualidade' como nova retórica conservadora no campo educacional. In: ; SILVA, T.T. Neoliberalismo, qualidade total e educação. Rio de Janeiro: Vozes, 1994.

GORZ, A. Immatériel: conaissence, valeur e capital. Paris, Galilée, 2003. GRAMSCI, A. Cadernos do cárcere. v. 2, 3. Rio de Janeiro: Civilização Brasileira, 2000. 1, 2004.

Escritos políticos. 1a. ed. Rio de Janeiro : Civilização Brasileira, v.

HABERMAS, J. Teoría de la acción comunicativa: crítica de razón funcionalista. Madrid, Taurus, 1987.

HUSSON, M. A miséria do capital. Lisboa: Terramar, 1996.

JESSOP, B. Capitalismo informacional e império: a celebração pós-marxista da hegemonia dos Estados Unidos. Outubro: revista do Instituto de Estudos Socialistas, São Paulo, n. 12, 2005.

KURZ, R. O colapso da modernização. Rio de Janeiro, Paz e Terra, 1992. MANACORDA, M.A. O princípio educativo em Gramsci. Porto Alegre: Artes Médicas, 1990.

MARX, K. Elementos fundamentales para la crítica de economía política (Grundrisse): 1857-1858. México: Siglo Veinteuno, v. 1 e 2, 1989.

NEVES, L.M.W. (Org.) Reforma universitária do governo Lula: reflexões para o debate. São Paulo: Xamã, 2004.

OFFE, C. Trabalho: a categoria-chave da sociologia? Revista Brasileira de Ciências Sociais. v. 4, n. 10. São Paulo, ANPOCS, junho de1989.

PRADO, E. Uma crítica à economia política do imaterial. Outubro: revista do Instituto de Estudos Socialistas, São Paulo, n. 11, 2004.

RIFKIN, J. O fim dos empregos. São Paulo: Makron Books, 1995.

SALAMA, P. A financeirização excludente: as lições das economias latinoamericanas. In: CHESNAIS, F. (Coord.). A mundialização financeira: gênese, custos, riscos. São Paulo: Xamã, 1998.

SBPC. Jornal da Ciência. Disponível em: <http//www.jornaldaciencia.org .br>. Acesso em: 01 mar. 2011.

WOOD, E.M. Democracia contra capitalismo. São Paulo: Boitempo Editorial, 2003.

Recebido em 01 de outubro de 2012.

Aprovado para publicação em 31 de outubro de 2012. 